\title{
High Resolution Wind Power and Wind Drought Models
}

\author{
Paula Carroll $^{a, b *}$, Lucy Cradden ${ }^{b, c}$, Mícheál Ó hÉigeartaigh ${ }^{a}$ \\ ${ }^{a}$ Centre for Business Analytics, University College Dublin, Dublin, Ireland \\ ${ }^{b}$ Energy Institute, University College Dublin, Dublin, Ireland \\ ${ }^{c}$ School of Earth Sciences, University College Dublin, Dublin, Ireland
}

\begin{abstract}
We present high resolution wind power statistical models fitted to meteorological data for the island of Ireland. We find that a discrete Burr model efficiently represents the number of consecutive hours of wind power availability. Burr models are also useful to model the complement of the wind power availability events, wind droughts, when wind speed is insufficient to produce wind power. The models developed in this study may be most useful at time resolutions less than 6 hours to capture zero power and short bursts of wind power potential. They could serve as a useful complement to other wind power modelling approaches such as MERRA reanalysis models. Wind power duration models, and their wind drought complements, also provide insights for investors on potential wind power availability at geographic locations.
\end{abstract}

\section{Keywords: Wind Power Model, Wind Drought Model, Discrete Count Model, Wind Energy Resource}

\section{Introduction}

The 2014 Intergovernmental Panel on Climate Change (IPCC) advocated for investment in low-carbon electricity production. Prior to that, the EU directive on the promotion of the use of energy from renewable sources directed member states to diversify the mix of energy towards renewable sources [1]. In response, EU member state prepared action plans; the Irish Government is aiming for $40 \%$ of electricity to be generated from Renewable Energy Sources (RESs) by 2020. Following the Paris Agreement and UN Sustainable Development Goals toward 2030, further climate action to limit global warming to below 2 degrees centigrade above pre-industrial levels is urgently needed.

Studies on the integration of renewable aim to understand the impact on the electricity grid and energy system balance, and articulate pathways toward $100 \%$ renewably powered electricity grids. The integration of significant amounts of wind power system impacts operational security, reliability and efficiency [2]. Overall, adding wind power to power systems reduces total operating costs and emissions, as wind replaces fossil fuels, but careful consideration of the market, grid design and investment decisions are required to achieve these savings.

${ }^{*}$ Corresponding author. Tel.: +35317164776

E-mail: paula.carroll@ucd.ie

(C) 2018 International Association for Sharing Knowledge and Sustainability

DOI: $10.5383 /$ ijtee.16.01.004
Mitigating for wind variability requires new approaches to system reserves, which are called on in the case of unexpected outages, or when the available wind differs from forecasts [3-5]. Approaches to wind power forecasting are described in [6]. Errors in wind power forecasts can cause the residual power to be over- or under-estimated. The residual power is the power that has to be delivered from conventional generation after power from renewable sources has been committed. Improving wind modelling and forecasting has been the focus of several researchers, see [7-9]. A key recommendation from the European Wind Integration Study [10], is the development of pan-European models which encapsulate more detailed regional and national models.

The uncertainty surrounding wind availability impacts on the investment decision making. Integration studies, such as [2], show that benefits accrue when RES is aggregated over geographic and energy balancing areas. Large balancing areas and aggregation benefits of wide areas help in reducing the variability and forecast errors of wind power as well as help in pooling more cost effective balancing resources. This diversity allows the (anti-)correlation of regional and renewable source type (such as wind/solar) to contribute a balance on aggregate and spread the risk of RES variability.

This gives the motivation for our Irish case study. We describe a one hour resolution statistical model of the potential wind power based on historical meteorological data. This model will 
serve as a complement to an aggregated wind power generation model using MERRA reanalysis wind speed data [11]. The MERRA model successfully reflects the measured wind production data for the period $2001-2014$ at greater than $6 \mathrm{~h}$ resolution. The correlation of the reanalysis model with actual output from 2006 onwards is $0.95-0.96$, with RMSE between $6.5 \%-8.5 \%$. At one- and three-hour time-horizons, the model tends to under-estimate the magnitude of ramps in capacity factor occurring with a particular frequency (i.e., for a given ramp magnitude, the model under-predicts the frequency of wind event occurrences). At horizons greater than or equal to six hours, the differences between the reanalysis model output and actual power are very small. This is reflective of a low spatial resolution reanalysis data inadequately representing variability at smaller time-horizons but also an effect of the temporal smoothing apparent in the data.

\subsection{Feast or Famine}

The EU Renewable Energy Directive requires the Transmission System Operators (TSOs) to prioritise renewable energy generation. However, wind power may have to be curtailed to ensure security and stability since wind power is an asynchronous source. The limit for system non-synchronous penetration (SNSP) in Ireland is set at $55 \%$. SNSP $=$ (wind generation + High Voltage Direct Current (HVDC) imports) / (system demand + HVDC exports).

In order to meet EU targets, EirGrid (the Irish TSO) aim to increase the SNSP limit to $75 \%$ by 2020 . The Irish SNSP operational limit was $55 \%$ in 2015 , it increased to $60 \%$ in 2017 , with trials of $65 \%$ SNSP in 2018.

Ging et al. [12] note that such curtailment is allocated pro-rata across all wind generators with an equal bias. As well as frequency and stability management issues, wind power may be curtailed due to operational or trans-mission constraints. Two major geographical constraint areas in Ireland are identified in [13]: the north-west and the south-west of Ireland. These constraints arose mainly because of network congestion issues, but also in some instances, because of system outage. Eirgrid note that outages caused by storms in the south west resulted in the output of windfarms in other areas being constrained to manage overloading lines. In addition, they note that curtailment arises mainly during the night time hours (between $11 \mathrm{pm}$ and 9am) due to the low overall system demand, when "must-run" conventional power plant may be able to meet the estimated residual demand.

Several metrics are used to quantify the productivity of a wind turbine. The capacity factor compares the actual power production of a turbine over a given time with the total power the turbine would have produced if it had operated at the rated power for the time frame.

The issues above arise when there is "too much" wind on the system. Whether such excess can be exported to neighbouring regions via grid interconnectors is studied in [2, 14], and depends on several factors including cross-border transmission capacity and trading arrangements. Brexit negotiations between the UK Government and the European Commission bring a new uncertainty component to energy security for Ireland, the full impact on energy policy in Ireland and Northern Ireland is yet to be determined.

A further challenge from wind variability risk arises during calm periods. The first quarter of 2015 saw surface wind speeds well below normal in most of the contiguous United States [15]. This reduced the electricity generation of most of the wind farms in the country, but particularly Texas, Oklahoma, and Kansas, where most of the biggest wind farms are concentrated. While this "wind drought" is likely an extreme event, companies experienced financial problems due to the lack of energy production and revenues. US investors want to understand what happened in 2015 .

Ireland is rich in wind resources and aims to meet its 2020 and future 2030 through significant wind power investment. Many of the issues particular to the Irish situation are set out in [16]. In 2015 2,363 MW of installed wind generation capacity accounted for $22.8 \%$ of the electricity generated and was the second largest source of electricity generation after natural gas [17]. However, 2016 was a quieter weather year; wind generation accounted for just $22.3 \%$ of electricity generation despite an increase in demand and installed wind generation $(2,827 \mathrm{MW})$, the balance of requirements was met by more gas.

\subsection{Research Questions}

Having given the context for our problem we highlight the research focus of this study which extends our work in [18]. Section 2 gives a brief overview of wind power modelling approaches. In this study we are particularly interested in the number of hours when power is theoretically produced (i.e., ignoring market and operational curtailment). We call this phenomenon a wind power event. We say a wind power event occurs when wind speed exceeds the cut-in threshold of a wind turbine so that power is produced. The end of the event occurs when the wind speed drops below the cut-out threshold. In this study we model $X$ the number of consecutive hours when wind power is produced. This allows us to characterise the distribution of the wind power events and the inter-event time distribution. The system of potential wind power is characterised by intermittent switching between periods of low activity and high activity bursts of potential power production. We are also interested in the complement of wind power events, when there is insufficient wind to produce wind power, so called wind droughts. We aim to answer the following research questions:

1. Which statistical models are useful to count the number of consecutive hours of wind power in a wind power event?

2. Are these models useful to count the number of consecutive hours of wind drought?

\section{Wind Modelling for Power Generation}

Analysis of long-term data on national or regional wind power output is required to understand, in particular, the variability in the production related to inter-annual and inter-decadal climatic patterns. Thirty years is generally understood to be the minimum required period in order to properly capture such fluctuations. Wind power generation has really only become a widespread contributor to power production in the last 5-10 years, with very few instances of wind farms older than 20 years, so historical records of output are not sufficient for long-term analyses, and thus simulations of such data are required.

Two main approaches are taken in the literature to developing simulations, both using wind speed data as input. The first uses historical records of measured wind speeds, typically held by meteorological institutions, and measured at 10 meters above ground level. The second relies on wind speeds as represented in "reanalysis" datasets.

Reanalysis data is that produced by running some form of a numerical weather prediction (NWP) model in hindcast mode, i.e. back in time. These models usually assimilate historical observations in some form, and are thereby expected to produce a homogeneous temporal sequence of historical weather.

The wind speed resulting from either historical measurement or reanalysis is then converted to wind power using manufacturers' turbine power curves. Fig. 1 shows an example of a reference 
power curve. Power is not generated below the cut-in speed $v_{c}$. The turbine reaches its rated power at $v_{r}$ and the turbine is shut down above its cut-out limit $v_{f}$ to prevent damage in high winds. Change et al. compare several models to describe wind turbine power output and conclude that quadratic models show better agreement between empirical performance and manufacturers' power curves [19].

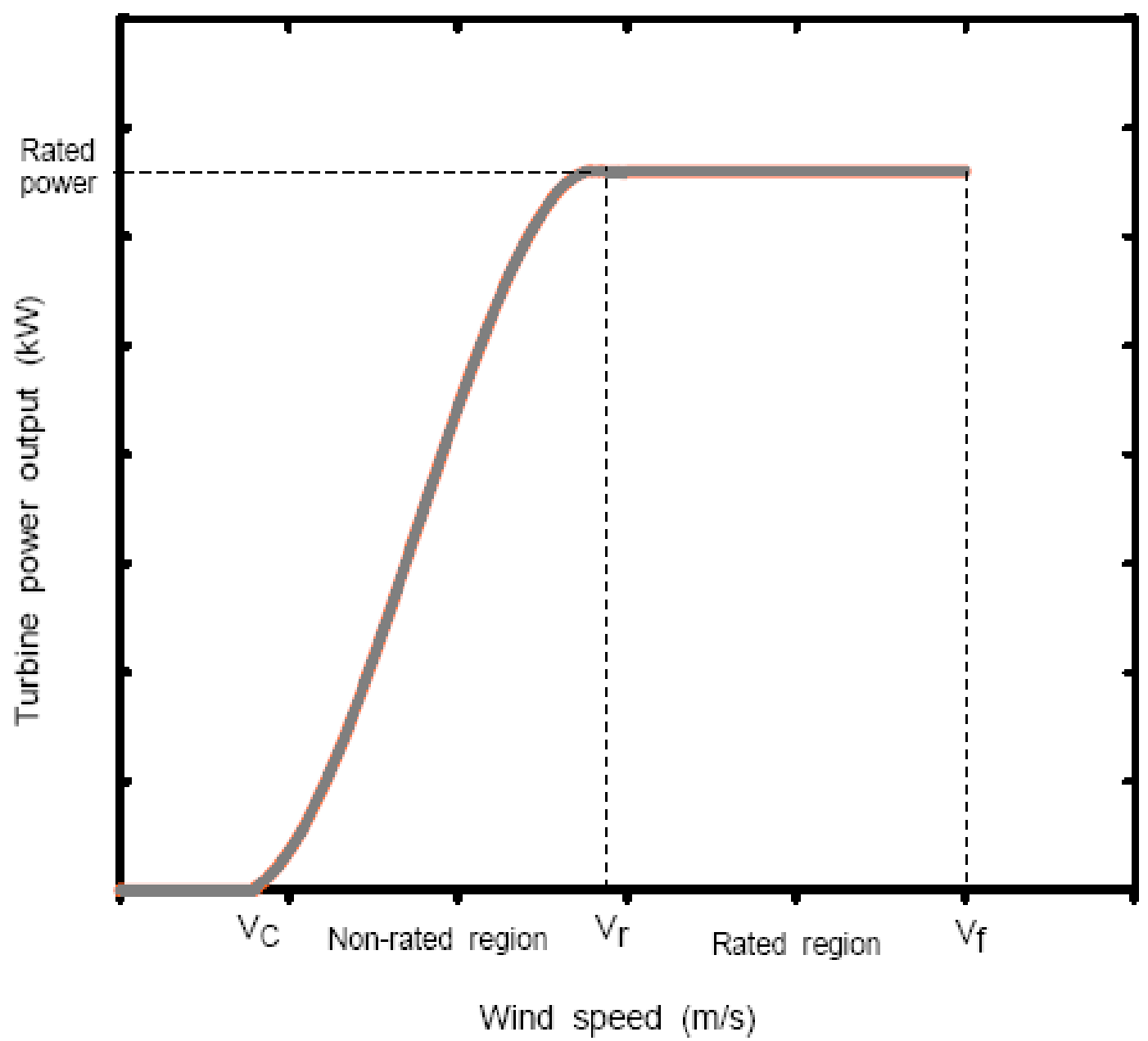

Fig.1. Sample Reference Power Transformation Curve [19]

Wind speeds either measured or modelled at 10 meter height need to be extrapolated to higher levels representing turbine hub height using a standard method, usually a power or log law. Models often produce output at multiple heights, so can be interpolated between levels to the hub height, or a relevant height output used directly.

Hub-height wind speeds are then transformed to MW of power production using a power curve which gives the expected output for a given speed and height. These are often published by turbine manufacturers for their particular device, but can also be adapted to reflect either farm or regional aggregate production, see for example [19].

Since power is only produced when the wind speed is within the operating range, we can consider the resulting wind power events as discrete temporal events whose duration and amplitude can be characterised. A similar observation in relation to wind speed is made in [20]. They note Weibull models are only applicable to non-zero wind speeds and exclude calm conditions from their analysis. In this study we focus on modelling the number of consecutive hours in a wind power event.

\section{Methodology}

Our approach to answering our research questions is to fit statistical count models to wind power data and assess the quality of fit. We extracted historical climate data for Ireland for the period 2005 - 2015 from Met Éireann, the Irish meteorological service [21].

We extracted the mean hourly wind speed in knots at 11 stations. These stations were chosen as almost complete data sets were available. At other stations significant amounts of data were missing, possibly due to instrument failure. While the met weather stations are not co-located with wind farms, the data are sufficient to evaluate the wind power event modelling framework. See Fig.2 for an indication of the locations of wind farms and met stations.

Wind speed was converted to $\mathrm{m} / \mathrm{s}$ at $10 \mathrm{~m}$ height. The expected power at $80 \mathrm{~m}$ hub height was then calculated for wind speeds between 3.5 and $25 \mathrm{~m} / \mathrm{s}$ using a power curve similar to that in Fig. 1 and assuming a single wind turbine of $3 \mathrm{MW}$ capacity. We then create a binary sequence for the period $2005-2015$ indicating whether power is produced in each hour or not: $W(t)$ $=1$ at time step $t$ if power is produced, otherwise $W(t)=0$. 
We let $X$ be the count of consecutive hours when wind power is produced. We fit statistical models for the distribution of $X$ and evaluate their usefulness compared to the empirical data.

Such models allow us to estimate how long wind power events are likely to last.
Similarly, we explore the sequences of zeros to understand the quiet periods between wind events when no wind power is likely to be available, i.e., the wind droughts.

The combination of the wind power events and wind droughts gives us insight to the potential performance of a site.

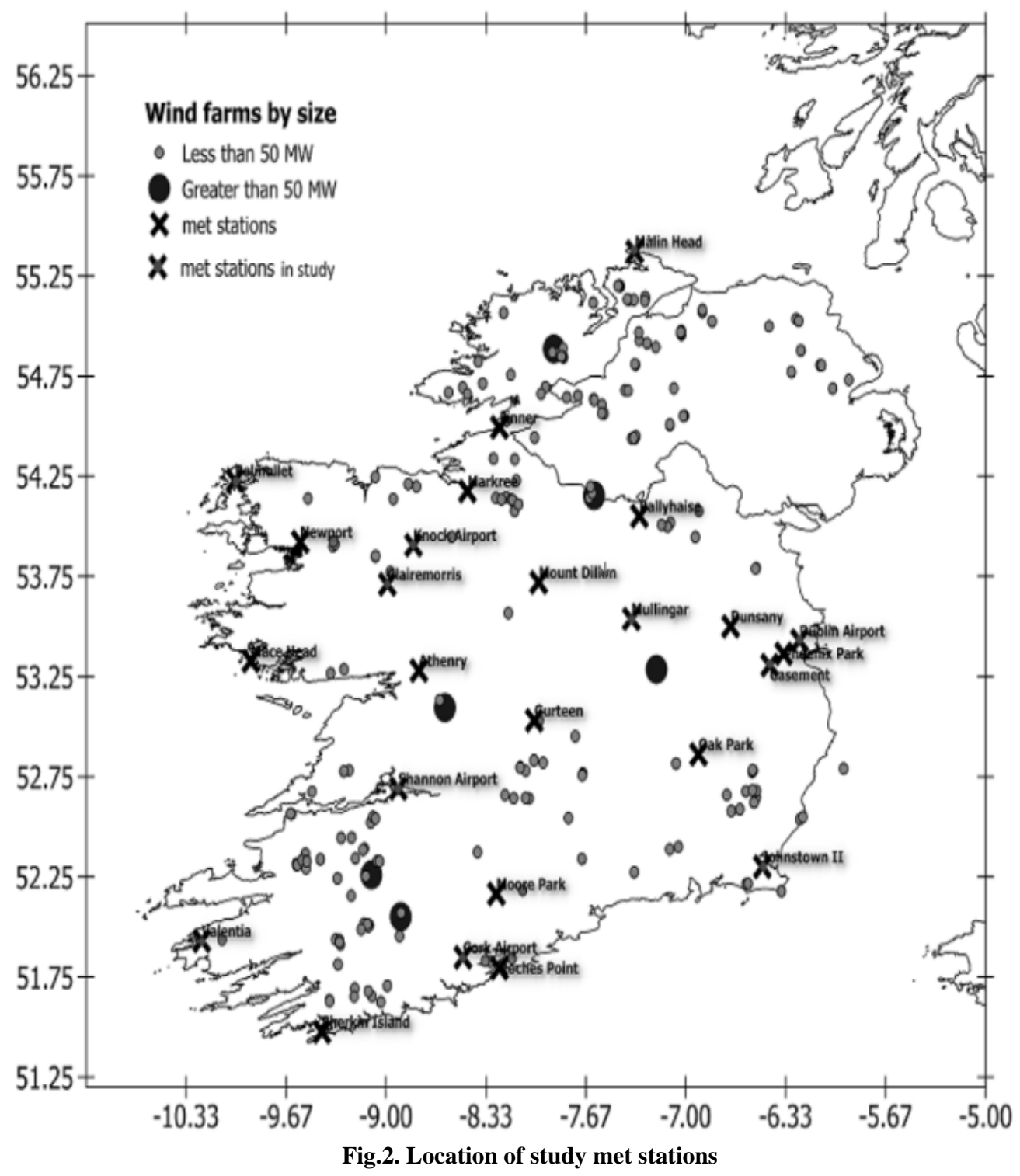

Poisson regression is often used as a baseline model for count data. They are sometimes used for telecommunications traffic modelling. The Poisson model generates very smooth traffic since the inter-arrival times follow an exponential distribution. The probability that an observation has count $x$ under the Poisson distribution is given by Eq. 1 .

$P(X=x)=\frac{\lambda^{x} e^{-\lambda}}{x !}$

However the assumption of equi-dispersion in the Poisson model is too restrictive for many empirical applications. In practice, the variance of observed count data often exceeds the mean i.e., over-dispersion is evident. In addition, Poisson models are too simple to capture the burstiness of real traffic, as the inter-arrival distributions have been observed to have heavier tails [22].
A more appropriate approach for bursty events such as wind power may be to consider hurdle or two-part models. In this case we consider that threshold conditions need to be reached for wind power events: wind must reach the cut in speed before power can be produced in our case study. This corresponds to surmounting a hurdle. Once over the hurdle, we then consider that the number of hours of wind power production may be modelled as a zero truncated Poisson distribution, i.e., the number of hours of potential power production is $\geq 1,0$ values are not observed.

So the wind power event model is a mixture of two components. The hurdle model keeps the zero-class disjoint from the nonzeros by modelling the non-zero as a truncated Poisson (ZTP) distribution. We use a finite mixture model approach to combine the probability of the "no power" event with a ZTP model for the hours when power is produced. We calculate probabilities using the complete conditional hurdle model in Eq. 2. 
$P(X=x)= \begin{cases}\theta & x=0 \\ (1-\theta) \frac{\lambda^{x} e^{-\lambda}}{\left(1-e^{-\lambda}\right) x !} & x \geq 1\end{cases}$

where $\theta$ is the probability that the hurdle will not be surmounted, i.e., the probability that power is not produced, and $\lambda$ is the conditional mean once power is produced.

In this way, we increase the probability of the zero outcome (compared to a standard Poisson model, Eq.1), and scale the remaining probabilities of non-zero Poisson counts so that they sum to one. This approach is often used to model counts such as the number of bus trips taken by bus passengers [23], the number of roots per successful plant root cutting [24] or the count of rare species [25].

A Burr distribution may offer an even more tailored fit to the heavy tailed empirical data. This unimodal distribution is defined by two shape parameters (corresponding to the skewness and kurtosis [26]. The continuous probability density function is given by Eq. 3 where $c$ and $k$ are the shape parameters. Values of $c \leq 1$ yield $L$-shaped distributions.

$f(x)=c k \frac{x^{c-1}}{\left(1+x^{c}\right)^{k+1}}$

An approach to discretising a continuous distribution is to round down values to the nearest integer. This allows a grouping of the continuous variable e.g., discretising continuous time into units of one hour. Further details of a discrete three parameter Burr pdf are discussed in [27]. A discrete Burr distribution is defined by three parameters, $B_{\theta}$ a scale parameter and shape parameters $B_{\alpha}$ and $B_{\gamma}$. We note that as electricity markets operate in discrete time steps, it is valid to follow this approach in attempting to model the number of hours in a wind power event, and also to count the hours of any wind drought non-events.

\section{Results and Analysis}

The models were fitted using SAS 9.4. Some exploratory analysis shows the variability in the empirical count data for the wind events in Table 1. Results for all weather stations exhibit similar characteristics. For the sake of brevity, we take Belmullet as an example to demonstrate learnings from our analysis, we justify this choice as it is first alphabetically in the list and is neither the worst not the best case.

There were 3,418 wind power events during the study period. The average number of hours in a wind event was 22.77 during the study period. The standard deviation at 37.44 hours is an indication of the variability that planners have to contend with. The skew and kurtosis figures indicate the peaky-ness and size of the right-hand tails of the distributions.

In general, we observe

Fig. 3 shows the distributions of wind speed and resulting power for a sample weather station, Belmullet. Other stations show exhibited distributions with some westerly locations exhibiting more consistently windy weather.

We see a Weibull distribution fitted to the wind speed data. This distribution is often used to model wind speed as it captures the right hand tail. Goodness of fit statistics indicate the Weibull distribution is a good fit to the wind speed data with Kolmogorov-Smirnov D, Anderson-Darling and Cramer-von Mises W-Sq distance values all returning $p<0.001$.

Approximately $19 \%$ of the time, no wind power is available at Belmullet as the recorded wind speed is below the cut-in speed $v_{c}=3.5$. Fig. 4 shows the wind power availability for a typical 3 MW wind turbine, having disregarded the calm hours of zero power output.

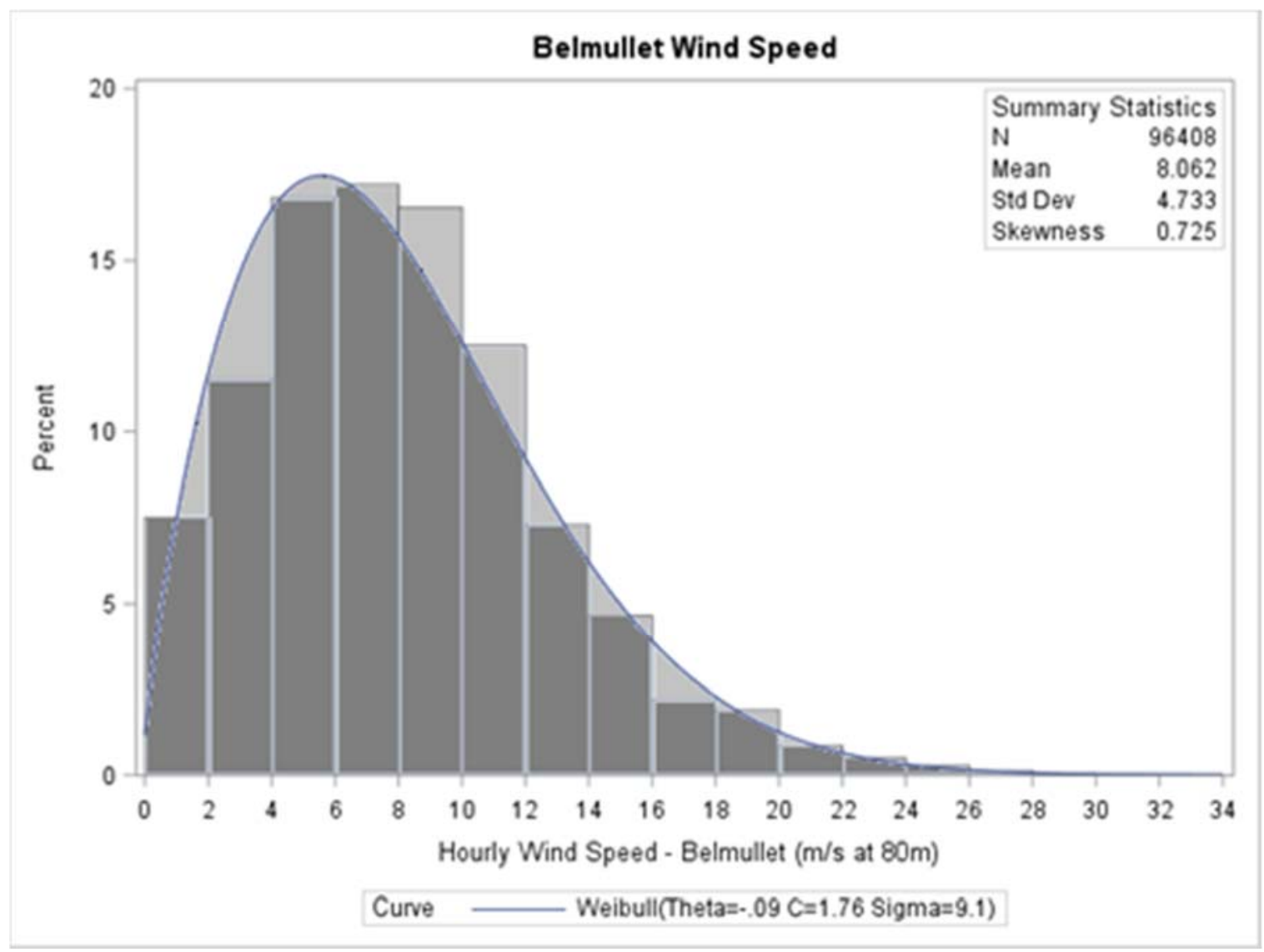

Fig.3. Wind speed $m / s$ at $80 \mathrm{~m}$, Belmullet Station 
Carroll et al. / Int. J. of Thermal \& Environmental Engineering, 16 (2018) 27-36

Table 1 Wine Event Descriptive statistics

\begin{tabular}{rrrrrrrrrrrr}
\hline & $\begin{array}{r}\text { Belmulle } \\
\mathrm{t}\end{array}$ & Casement & $\begin{array}{r}\text { Claremorri } \\
\mathrm{s}\end{array}$ & Cork & Dublin & $\begin{array}{l}\text { Johns- } \\
\text { town }\end{array}$ & Knock & $\begin{array}{l}\text { Malin } \\
\text { Head }\end{array}$ & Mullingar & Shannon & Valentia \\
\hline $\mathrm{N}$ & 3418 & 4048 & 5046 & 4342 & 3556 & 4893 & 4028 & 2826 & 4737 & 4724 & 4133 \\
Mean & 22.77 & 17.33 & 13.11 & 17.25 & 22.68 & 12.49 & 18.51 & 30.48 & 10.82 & 14.79 & 16.71 \\
Std Dev & 37.44 & 34.12 & 21.95 & 26.77 & 39.77 & 19.17 & 28.64 & 54.21 & 16.44 & 24.50 & 28.09 \\
Skew & 3.16 & 4.89 & 6.39 & 3.40 & 4.18 & 3.75 & 2.97 & 3.65 & 3.56 & 3.47 & 3.94 \\
Kurtosis & 14.38 & 35.45 & 101.15 & 17.17 & 27.66 & 21.89 & 11.83 & 18.49 & 18.86 & 16.50 & 24.47 \\
Median & 7 & 5 & 5 & 6 & 8 & 6 & 6 & 9 & 4 & 5 & 6 \\
Mode & 1 & 1 & 1 & 1 & 1 & 1 & 1 & 1 & 1 & 1 & 1 \\
Range & 415 & 508 & 543 & 288 & 553 & 275 & 283 & 581 & 185 & 258 & 393 \\
\hline
\end{tabular}

Fig. 5 shows the early part of the Zero Truncated Poisson (ZTP) distribution. For exhibition purposes, we show events which last up to 24 hours for the sample weather station Bemullet. In fact, the right hand tail of the distribution is very long, with a small number of events lasting up to 415 hours. This means that it in sufficiently windy over up to 415 consecutive hours to produce power at the Belmullet station. On the other hand, in Fig. 5 we can see a large number of short events, $\sim 31 \%$ of the wind events last for just one hour. These events are book-ended by hours, or sequences of hours of zero power.

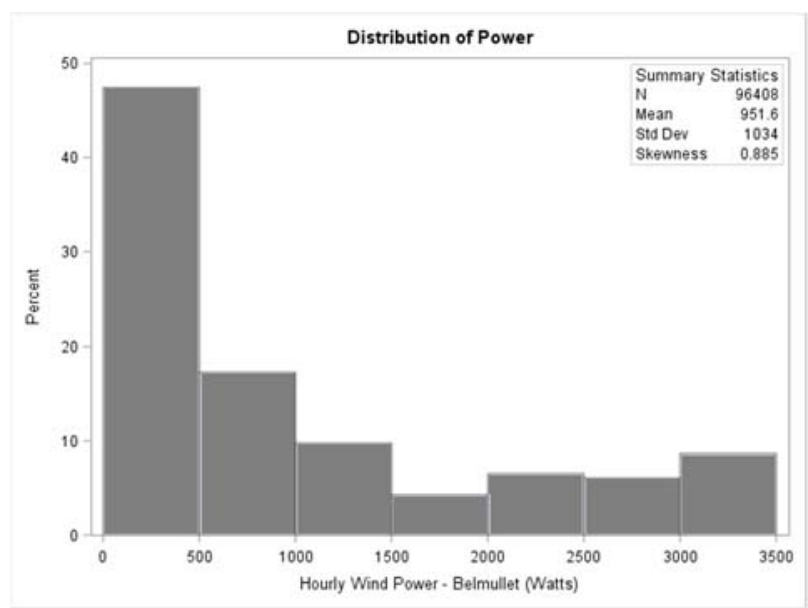

Fig.4. Wind Power $(k W)$, Belmullet Station

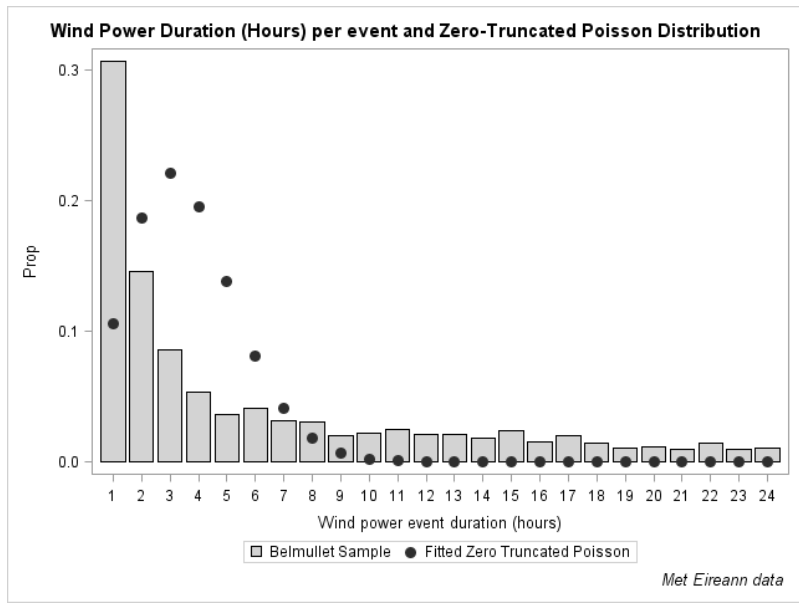

Fig.5. ZTP fitted to Bellmullet Wind Power Event

Many of the observed wind power events are of long duration. In fact $P(X>24) \approx 0.65$ for the bulk of the sample sites. The wind power event duration distribution has a long tail, a small number of events can run for several hundred hours when the weather is persistently windy. The single parameter Poisson $(\lambda$ $=\mu$ ) is too restrictive compared to other distributions that specify additional parameters such as the variance. The Zero Truncated Poisson (ZTP) model does not help to fully explain the long tail, i.e., there are a small number of very long sequences evident in the empirical data.

Fitting a generalised linear Poisson regression model also yielded a poor fit. In addition, the basic assumptions such as constant decay do not hold. The observed wind power events are more bursty in nature.

We see in Table 2 that the ZTP hurdle models offer a better fit than standard Poisson models. The likelihood of no power or a non-zero number of hours of power is more closely approximated. $A I C_{1}$ is the AIC for a Poisson model, $A I C_{2}$ for a ZTP model. Lower AIC values were achieved e.g., the Belmullet ZTP hurdle model AIC of 169,703 compares to 440,520 for the Poisson model. $\lambda_{1}$ and $\lambda_{2}$ are the estimated mean values for the Poisson and ZTP models.

$\theta$ is the estimated likelihood of no power in the ZTP model. For example $\theta=0.16$ for Belmullet compares to the estimated value of $19 \%$, i.e., $19 \%$ of the time no wind power is available due to low wind speeds. Once over the hurdle, the estimate for the average number of hours per wind event is 22.77 .

The lower AIC scores indicate a better model fit of the ZTP. Table 2 shows that the ZTP model fit metric follow the same pattern across the sample meteorological sites, and that the ZTP models provide more useful information that a simple Poisson. The ZTP model for Mullingar, for example, shows an estimate of no power availability of 0.09 , and average wind event duration of 10.81 hours. However, we still have not accounted fully for the over dispersion that is apparent in the empirical data. In further testing of finite mixture models, a zero truncated discreteised Burr model is selected as better fitting the zerotruncated count data, compared to Exponential, Gamma, Igauss, Lognormal, Pareto, Gpd, or Weibull distributions.

For example, the three parameters of a zero truncated discrete Burr model are $B_{\theta}=0.96633, B_{\alpha}=0.00429, B_{\gamma}=115.45141$, the fitted and empirical distributions (EDF) for a sample station (Belmullet) are shown in Fig. 6.

Again using Belmullet as an example, we show details of the finite mixture model fit metrics in Table 3 including Kolmogorov-Smirnov D (KS), Anderson-Darling (AD) and Cramer-vonMises W-Sq (CvM) values. The best model under each metric is indicated by an $*$.

We observed similar results for the other stations, with the discrete Burr generally the best fit considering most metrics. While the Burr model may offer a better fit for the zero truncated count data, the wind power modelling community may be more familiar with the Weibull model so this may offer a useful alternative. 


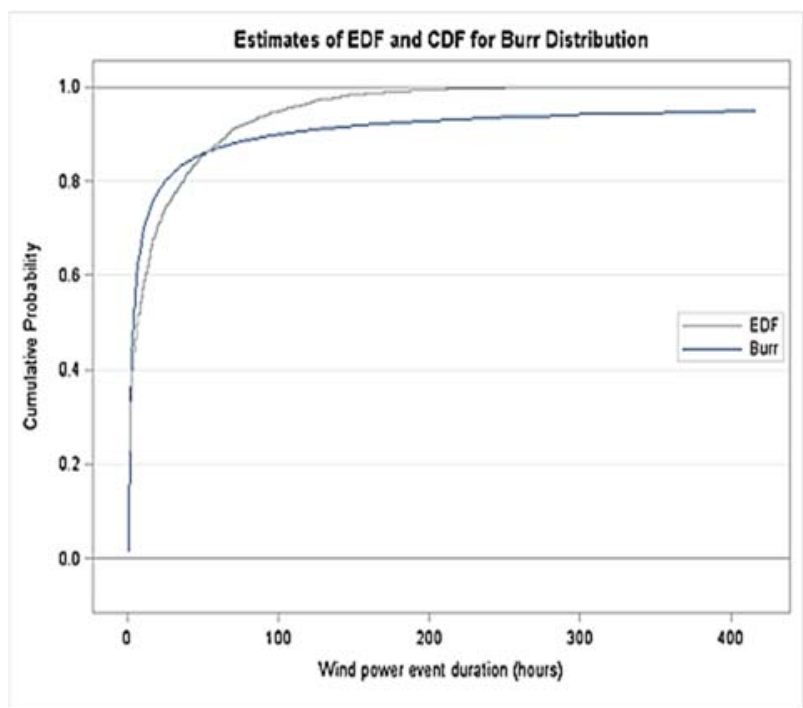

Fig.6. Burr Model Fit, Belmullet
We next turn our attention to the wind drought events. Adopting a similar approach to our treatment on the wind power events, we consider the sequences of zeros when no power is produced.

Table 4 shows the summary statics for the calm conditions when wind speed is insufficient to produce wind power. We see the wind droughts are considerable shorter and less variable than the wind power events at the same locations (shown in Table 1). The term "drought" is too severe for these conditions in Ireland; rather they are relatively short periods of calm.

Fig.7 shows an example of the wind drought duration, again using Belmullet as an example. We see that over $60 \%$ of these events last only one hour. This again demonstrates the variability of wind as an energy resource, these one hour intervals of low wind, are interspersed with hours of stronger wind that are capable of producing power.

We adopt the same methodology and fit statistical models for the counts of consecutive hours of no power. Table 5 shows the model fit metrics. Fig. 8 shows the empirical and cumulative Burr distribution for Belmullet.

Table 2. Poisson and ZTP Hurdle Model

\begin{tabular}{|c|c|c|c|c|c|c|c|c|c|c|c|}
\hline & Belmulle & Casemem & Claremorri & & & Johnstow & & Malin & Mullinga & Shanno & Valenti \\
\hline & $\mathrm{t}$ & $\mathrm{t}$ & $\mathrm{s}$ & Cork & Dublin & $\mathrm{n}$ & Knock & Head & $\mathrm{r}$ & $\mathrm{n}$ & a \\
\hline AIC & & & & 40062 & 43057 & & 41229 & & & & \\
\hline 1 & 440520 & 435180 & 380170 & 9 & 3 & 363838 & 4 & 439411 & 332227 & 398604 & 412190 \\
\hline $\begin{array}{l}\lambda_{1} \\
\text { AIC }\end{array}$ & 3.54 & 2.32 & 1.88 & $\begin{array}{r}2.9 \\
15677\end{array}$ & $\begin{array}{r}4.18 \\
17607\end{array}$ & 1.52 & $\begin{array}{r}2.88 \\
15729\end{array}$ & 6.57 & 1.03 & 2.23 & 2.2 \\
\hline 2 & 169703 & 176568 & 151755 & 8 & 7 & 136217 & 0 & 188792 & 122261 & 161077 & 156238 \\
\hline$\lambda_{2}$ & 22.77 & 17.33 & 13.11 & 17.25 & 22.68 & 12.49 & 18.51 & 30.48 & 10.81 & 14.79 & 16.71 \\
\hline$\theta$ & 0.16 & 0.13 & 0.14 & 0.17 & 0.18 & 0.12 & 0.16 & 0.22 & 0.09 & 0.15 & 0.13 \\
\hline
\end{tabular}

Table 3 Finite Mixture Model Fit (Belmullet)

\begin{tabular}{llllllll}
\hline & $\begin{array}{l}-2 \text { Log } \\
\text { Likelihood }\end{array}$ & AIC & AICC & BIC & KS & AD & CvM \\
\hline Burr & $25239^{*}$ & $25245^{*}$ & $25245^{*}$ & $25263^{*}$ & 12.28842 & 1046 & 46.24458 \\
Exp & 28201 & 28203 & 28203 & 28210 & 16.20701 & 1247 & 120.9343 \\
Gamma & 27146 & 27150 & 27150 & 27163 & 8.43989 & 497.4116 & 27.90341 \\
Igauss & 25983 & 25987 & 25987 & 25999 & 8.57996 & 568.3789 & 27.38194 \\
Logn & 26379 & 26383 & 26383 & 26395 & 7.53397 & 512.6546 & 23.42013 \\
Pareto & 26688 & 26692 & 26692 & 26704 & 7.12337 & 473.1846 & 18.69652 \\
Gpd & 26688 & 26692 & 26692 & 26704 & $7.12337^{*}$ & 473.1846 & 18.69652 \\
Weibull & 26878 & 26882 & 26882 & 26894 & 8.64439 & $450.71542^{*}$ & $18.10364 *$ \\
\hline
\end{tabular}

Table 4 Wind Drought Event Descriptive Statistics

\begin{tabular}{lrrrrrrrrrrrr}
\hline & Belmullet & Casement & Claremorris & Cork & Dublin & Johnstown & Knock & Malin Head & Mullingar & Shannon & Valentia \\
\hline N & 3417 & 4047 & 5045 & 4342 & 3555 & 3555 & 4027 & 2825 & 4736 & 4736 & 4132 \\
Mean & 5.08 & 5.93 & 5.53 & 4.58 & 4.23 & 4.23 & 4.99 & 3.39 & 8.79 & 8.79 & 6.18 \\
Std Dev & 6.67 & 8.28 & 8.10 & 5.77 & 4.63 & 4.63 & 7.02 & 3.87 & 14.16 & 14.16 & 8.01 \\
Skew & 3.40 & 4.57 & 4.77 & 3.36 & 2.63 & 2.63 & 4.01 & 3.88 & 4.63 & 4.63 & 3.41 \\
Kurtosis & 18.72 & 40.73 & 42.44 & 18.15 & 11.44 & 11.44 & 25.07 & 30.16 & 35.73 & 35.73 & 20.40 \\
Median & 2 & 3 & 2 & 2 & 2 & 2 & 2 & & 2 & 3 \\
Mode & 1 & 1 & 1 & 1 & 1 & 1 & 1 & 3 & 1 & 1 \\
Range & 74 & 141 & 145 & 68 & 48 & 48 & 88 & 61 & 214 \\
\hline
\end{tabular}


Table 5 Wind Drount Model Fit Metrics (Belmullet)

\begin{tabular}{|c|c|c|c|c|c|c|c|}
\hline & $\begin{array}{l}-2 \text { Log } \\
\text { Likelihood }\end{array}$ & AIC & $\mathrm{AICC}$ & $\mathrm{BIC}$ & $\mathrm{KS}$ & $\mathrm{AD}$ & CvM \\
\hline Burr & $14640^{*}$ & $14646^{*}$ & $14646^{*}$ & $14664 *$ & 19.48461 & 2230 & 138.1602 \\
\hline Exp & 17945 & 17947 & 17947 & 17953 & $10.77064 *$ & 861.3653 & 72.00962 \\
\hline Gamma & 17944 & 17948 & 17948 & 17961 & 10.93088 & 873.9323 & 74.14133 \\
\hline Igauss & 16670 & 16674 & 16674 & 16687 & 12.77272 & 925.8673 & 72.65638 \\
\hline $\log n$ & 17030 & 17034 & 17034 & 17046 & 12.14152 & 887.0631 & 68.08558 \\
\hline Pareto & 17718 & 17722 & 17722 & 17735 & 13.07159 & $663.75545^{*}$ & $34.27674 *$ \\
\hline Gpd & 17718 & 17722 & 17722 & 17735 & 13.07159 & 663.7555 & 34.27675 \\
\hline Weibull & 17914 & 17918 & 17918 & 17931 & 11.82913 & 760.5087 & 53.81589 \\
\hline
\end{tabular}

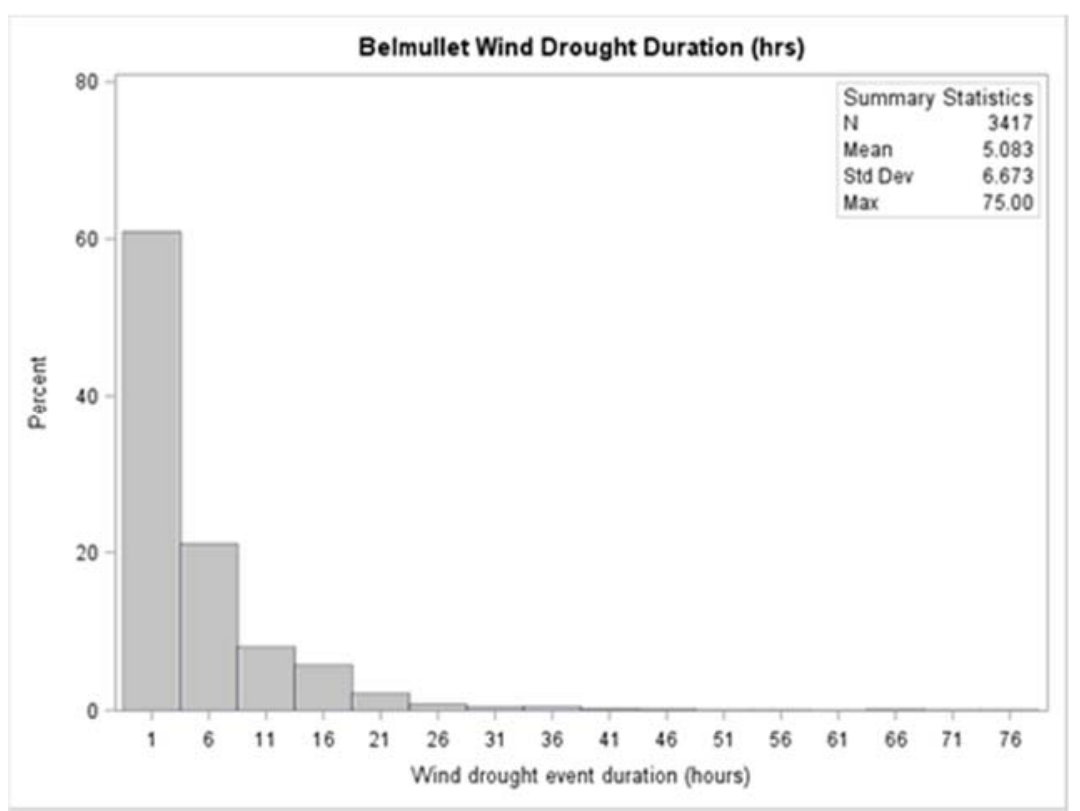

Fig.7. Wind Drought Duration (Belmullet)

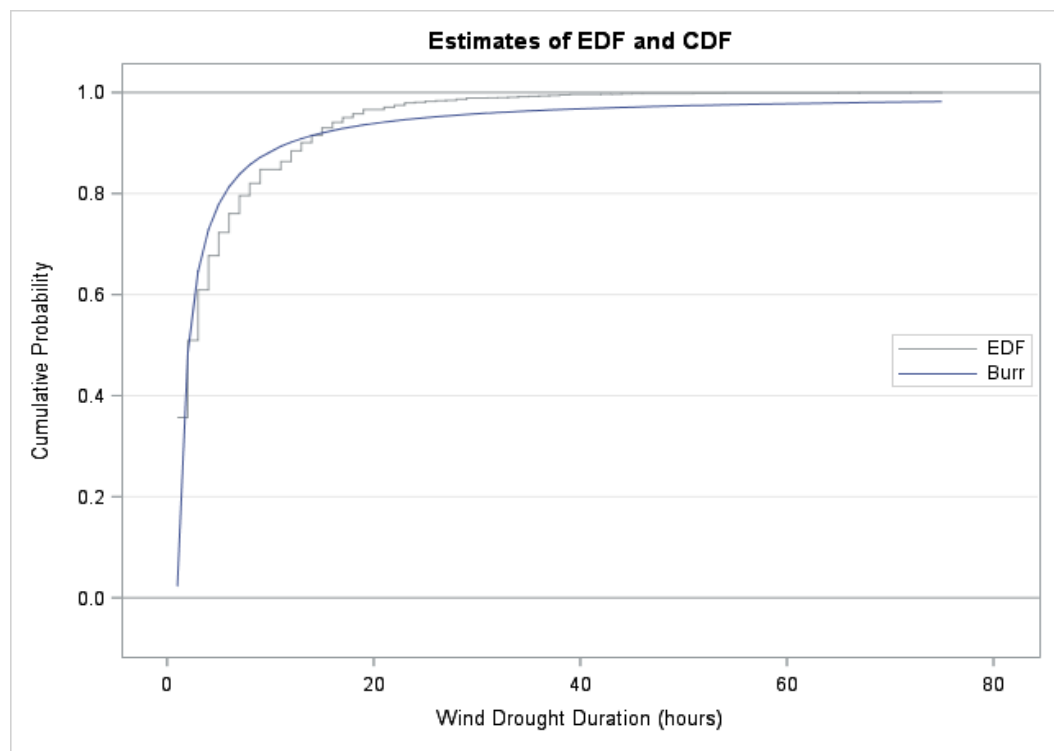

Fig.8. Wind Drought Burr Models Fir (Belmullet) 


\section{Conclusion}

One of the major concerns of renewable energy sources is their intermittency. The fact that the tails observed in the empirical data are so long is indicative of persistent availability of wind power in geographic locations like Ireland. The overall appearance of the empirical distribution of the wind event duration is an aggregation of correlated bursty trains, some of which are very long.

We conclude that Poisson models do not adequately capture the long tail of the empirical distribution. The Zero truncated Poisson models offer a better fit but still over estimate the early part of the distribution and under estimate the tail area. The discretised Burr model offers an adequate description and could provide a useful complement to other wind power modelling approaches such as the MERRA reanalysis models in [11]. In particular, the models developed in this study may be most useful for early part of the distribution (at time resolutions $\leq 6$ hours) to capture zero power and short bursts of wind power potential.

A limitation of our work is the assumption of independence of the events. Over-dispersion in count data may be due to failure of the assumption of independence of events which is implicit for example in the Poisson process. In the case of wind power, it is likely that the count of consecutive hours of power production are correlated and not independent. Statistical models such as Poisson rely on assumptions that there exists a well defined mean and variance of the distribution. Some types of events have no natural sequence length. The activity is clustered in sequences of self-similar events or "bursts". Geophysical time series are frequently autocorrelated because of inertia or carryover processes in the physical system. The moving low pressure systems in the atmosphere might impart persistence to weather effects such as wind or rain. Positive autocorrelation might be considered a specific form of persistence. For example, the likelihood of the next hour being rainy is greater if it is rainy now than if it is currently dry. This is of

Further extensions of our work will address the temporal correlation, and also the spatial correlation between sites. "Bursty" models that explain the switching between periods of high and low activity will be useful to understand fully the potential of wind to provide renewable energy and meet clean energy objectives.

\section{Acknowledgments}

Lucy Cradden would like to acknowledge funding from the UCD Energy21 program (Grant agreement number: 609401), co-financed through the Marie Skłodowska-Curie FP7PEOPLE-2013-COFUND program.

\section{References}

[1] COM, Energy 2020 a strategy for competitive, sustainable and secure energy, Tech. Rep. 639, European Union (2010).

URL http://ec.europa.eu/energy/publications/doc/2011\_energ y2020\en.pdf

[2] Holttinen, H., Meibom, P., Orths, A., Lange, B., O'Malley, M., Tande, J. O., ... \& Smith, J. C. Impacts of large amounts of wind power on design and operation of power systems, results of IEA collaboration. Wind Energy, 2011;14(2): 179-192, DOI: 10.1002/we.410.
[3] Holttinen, H., Milligan, M., Ela, E., Menemenlis, N., Dobschinski, J., Rawn, B., ... \& Detlefsen, N. K. Methodologies to determine operating reserves due to increased wind power. IEEE Transactions on Sustainable Energy, 2012; 3(4): 713-723. DOI: 10.1109/TSTE.2012.2208207

[4] Flynn, D., Rather, Z., Ardal, A., D'Arco, S., Hansen, A. D., Cutululis, N. A., ... \& Smith, C. Technical impacts of high penetration levels of wind power on power system stability. Wiley Interdisciplinary Reviews: Energy and Environment, 2017; 6(2): 1-19. DOI: 10.1002/wene.216.

[5] Katzenstein, W., Fertig, E., \& Apt, J. The variability of interconnected wind plants. Energy Policy, 2010; 38:8, 4400-4410, DOI:10.1016/j.enpol.2010.03.069.

[6] A. M. Foley, P. G. Leahy, A. Marvuglia, E. J. McKeogh, Current methods and advances in forecasting of wind power generation, Renewable Energy 37 (1) (2012) 1-8. 4.

[7] C. Lowery, M. O'Malley, Impact of wind forecast error statistics upon unit commitment, IEEE Transactions on Sustainable Energy 3 (4) (2012) 760-768. 5.

[8] P. Pinson, Wind energy: Forecasting challenges for its operational management, Statistical Science 28 (4) (2013) 564-585. 6.

[9] C. Sweeney, P. Lynch, Adaptive post-processing of shortterm wind forecasts for energy applications, Wind Energy 14 (3) (2011) 317-325. 7.

[10] W. Winter, European wind integration study (EWIS) final report, 2010, p. 25. URL http://www.windintegration.eu/downloads/library/EWIS $\backslash$ Final $\$ Report.p $\underline{\mathrm{df}}$

[11] L. C. Cradden, F. McDermott, L. Zubiate, C. Sweeney, M. O'Malley, A 34-year simulation of wind generation potential for Ireland and the impact of large-scale atmospheric pressure patterns, Renewable Energy 106 $\begin{array}{llllll}\text { (Supplement } & \text { C). 2017; } 165 \quad-\quad 176 .\end{array}$ DOI:10.1016/j.renene.2016.12.079.

[12] J. A. Ging, M. E. Glavin, D. J. Crilly, E. P. Kennedy, P. A. O'Donnell, J. E. Sustman, Spatio-temporal analysis of possible wind generation output reductions for the Irish transmission system with a high penetration of renewables, IET Renewable Power Generation. 2014; 8:3, 230-239.

[13] EirGrid, Annual renewable energy constraint and curtailment report 2014, Tech. rep., accessed June 2016 (2014). URL http://www.eirgridgroup.com/sitefiles/library/Annual-Renewable-Constraint-andCurtailment-Report- 2014.pdf

[14] E. Denny, A. Tuohy, P. Meibom, A. Keane, D. Flynn, A. Mullane, M. O'Malley, The impact of increased interconnection on electricity systems with large penetrations of wind generation: A case study of Ireland and Great Britain, Energy Policy. 2010; 38(11): 69466954. DOI: 10.1016/j.enpol.2010.07.011.

[15] Lledó, L., Bellprat, O., Doblas-Reyes, F. J., \& Soret, A. Investigating the effects of Pacific sea surface temperatures on the wind drought of 2015 over the United States. Journal of Geophysical Research: Atmospheres 2018; 123:10, 4837-4849 DOI: 10.1029/2017JD028019 
[16] J. O’Sullivan, A. Rogers, D. Flynn, P. Smith, A. Mullane, M. O'Malley, Studying the maximum instantaneous nonsynchronous generation in an island system-frequency stability challenges in Ireland, IEEE Transactions on Power Systems. 2014; 29(6): 2943-2951. DOI: 10.1109/TPWRS.2014.2316974.

[17] Eirgrid, Annual Renewable Constraint and Curtailment Report. $2016 . \quad$ http://www.eirgrid.ie/sitefiles/library/EirGrid/Annual-Renewable-Constraint-andCurtailment-Report-2016-v1.0.pdf

[18] Carroll, Paula; Cradden, Lucy; Ó hÉigeartaigh, Mícheál; High Resolution Wind Power Models - an Irish Case Study. Procedia Computer Science. 2018; 130:704-711. DOI:10.1016/j.procs.2018.04.124

[19] T.-P. Chang, F.-J. Liu, H.-H. Ko, S.-P. Cheng, L.-C. Sun, S.-C. Kuo, Comparative analysis on power curve models of wind turbine generator in estimating capacity factor, $\begin{array}{lllll}\text { Energy. } & 2014 ; & 73: & 88 & -\end{array}$ DOI:10.1016/j.energy.2014.05.091.

[20] N. Nawri, G. N. Petersen, H. Bjornsson, A. N. Hahmann, K. Jnasson, C. B. Hasager, N.-E. Clausen, The wind energy potential of Iceland, Renewable Energy 69 (Supplement C) 2014; $290 \quad$ - 299. DOI:10.1016/j.renene.2014.03.040.

[21] Met Éireann, Historical data, accessed June 2016, data licensed under a Creative Commons Attribution-
ShareAlike 4.0 International licence (2016). URL http://www.met.ie/climate-request/

[22] V. Paxson, S. Floyd, Wide area traffic: the failure of Poisson modeling, IEEE / ACM Transactions on Networking (ToN). 1995; 3 (3): 226-244.

[23] Cameron, A. C., \& Trivedi, P. K. Essentials of Count Data Regression, A Companion to Theoretical Econometrics. 2001; 331-348. Malden, MA: Blackwell.

[24] M. Ridout, C. G. Demétrio, J. Hinde, Models for count data with many zeros, in: Proceedings of the XIXth international biometric conference. 1998; Vol. 19, 179192.

[25] A. Welsh, R. Cunningham, C. Donnelly, D. Lindenmayer, Modelling the abundance of rare species: statistical models for counts with extra zeros, Ecological Modelling. 1996; 88 (1): 297 - 308. DOI:10.1016/03043800(95)00113-1.

[26] P. R. Tadikamalla, A look at the burr and related distributions, International Statistical Review/Revue Internationale de Statistique. 1980; 337-344. 20.

[27] Para, B. A., \& Jan, T. R. On Discrete Three Parameter Burr Type XII and Discrete Lomax Distributions and Their Applications to Model Count Data from Medical Science. Biom Biostat. Int. J. 2016; 4(2); 00092. 